\title{
La Academia Gaditana de Bellas Artes, policía de la buena arquitectura. Cincuenta años de informes facultativos. 1835-1885
}

JUAN R. CIRICI

Traigo a consideración en el presente trabajo el importante papel que sobre la arquitectura que se Jleva a cabo en la provincia, la buena construcción, el buen gusto y ornato, juega a lo largo de todo el siglo XIX la Academia Provincial de Bellas Artes de Cádiz. Circunstancia esta que, desde lo particular a lo universal, se podría extrapolar a otras Academias provinciales y, en especial y ámbito general, a la de Bellas Artes de San Fernando de Madrid.

Cási desde su fundación, y así queda recogido en el interesante trabajo sobre la Escuela de Nobles Artes de Cádiz realizado por la profesora Gascón Heredia y publicado por la Academia gaditana, la institución, Escuela de Nobles Artes primero y posterior Academia Nacional, junto a su función docente y demás encaminadas a la creación y promoción de las artes y la cultura "cumplió en no pocas ocasiones otras labores de policía artística" (1).

Creada en 1788, la Escuela de Nobles Artes gaditana tenía como principal misión', y así nos consta en sus orígenes, la enseñanza del dibujo, cuyos antecedentes habría que encontrar en el proyecto del Regidor Huarte y la fundación de la Escuela de Plateros, así como la de otras materias, auxiliares y complementarias al oficio artístico, tales como la aritmética y la geometría, caso de la Escuela del Conde O'Reilly, con la que formar, con la mayor perfección posible, en el arte y en la técnica a las nuevas generaciones de aprendices y artesanos. Es por ello que apenas unos meses después del solemne "Acto de Erección y Establecimiento...", 29 de noviembre, en el que quedan fijados la junta rectora y la organización de los estudios, abriese sus puertas al alumnado la Escuela, 27 de marzo de 1789, tomando como modelo estatutario, a menor escala, el de la Real Academia fernandina.

Sin embargo y en la medida que la Escuela ampliaba con éxito sus actividades, fondos bibliográficos y nuevas ediciones, premios, becas y exposiciones, ampliaba también su proyección social e institucional. En términos generales, y de Gascón Heredia, la Escuela de Nobles Artes pasa a cumplir "funciones que

(1) Ma Teresa GASCON HEREDIA. Estudio Histórico de la Escuela de Nobles Artes de Cádiz: 1789-1842. Pág. 415. Real Academia de Bellas Artes. Cádiz, 1989.

DOI: http://dx.doi.org/10.25267/Trocadero.1995.i6.20 
iban encaminadas a la supervisión, control y análisis minucioso de todos aquellos asuntos que se relacionaran con la mejora de las artes en la provincia". Más particular y concreto, la Escuela hasta 1842, y Academia después, ejercerá, al margen de la enseñanza, un variado y efectivo control de las artes en la provincia que abarcará desde aspectos puramente formales y estilísticos a los de la denuncia reivindicativa, consulta y aprobación de nuevas obras, depósito y conservación de las ya existentes y vigilancia del patrimonio monumental históricoartístico.

Entre las primeras medidas o acuerdos de la Escuela de Nobles Artes de carácter no docente destaca por su trascendencia la prohibición de importar mármoles y jaspes labrados de Italia al considerarse que perjudicaba a los artífices locales y nacionales (2). Junto a la promoción de los artistas propios y, como señala Falcón (3), "la explotación a fondo de las canteras de la comarca" la decisión rompía con la tradición de los mármoles genoveses en Cádiz, retablos y fachadas, y que tan notables muestras había dejado patente en los siglos XVI y XVIII. Años después, en 1817, y en esta misma línea, los directores de las clases de Pintura, Escultura y Arquitectura solicitarán a la Junta de la Escuela que reclame al gobierno de la nación la prohibición de la entrada de obras facturadas en el extranjero por estar "...realizadas en tonos de verdadera barbarie y faltas de buen gusto..." en beneficio de las nacionales "...por ser de mas bajo precio" (4).

En estos primeros años de existencia la Escuela visará, y aprobará, un proyecto de monumento en honor de la Constitución de 1812, a levantar en la Iglesia de San Felipe Neri, 1821, recogerá en depósito un cuadro de "El juicio final", procedente de la exclaustración del Convento de los Carmelitas Descalzos, 1822, treinta y tres pinturas de la Cartuja de Jerez y cinco mas del Convento del Carmen de Cádiz, 1823, y ante la petición de la Academia de San Fernando de Madrid de una relación de los edificios "de más grande Arquitectura comprendidos en el distrito..." una comisión nombrada al efecto y compuesta por los profesores Velázquez, Roca y Espinosa y presidida por el académico de honor Sr. Solano elaborará un informe en el que sorprendentemente se declaraba "...que en esta demarcación provincial no existe edificio alguno que reúna esas circunstancias...", 1836, entre otros cometidos (5).

Mayor interés para nosotros, por introducirnos en el tema, es el seguimiento que sobre la apertura de la plaza de Mina, en Cádiz, ejerce la institución. Pese a dirigir los trabajos el entonces Arquitecto Mayor de Ciudad y a la vez profesor de la clase de Arquitectura de la Escuela Juan Daura se formará una comisión mixta Ayuntamiento-Academia encargada del control y financiación de las obras. Obras que se prolongarán durante dos años, 1836-1838, quedando pendiente aún algunos aspectos de su exorno (6). La representación académica será ostentada por D. Francisco Van Herch. Poco después, en un lateral de la plaza, y construida por

(2) Junta de 3 de marzo de 1979. Tomo 1․ Libros de Actas de Juntas Académicas. Archivo Academia de Bellas Artes de Cádiz.

(3) Teodoro FALCON MARQUEZ. Torcuato Benjumeda y la Arquitectura Neoclásica en Cádiz. Pág. 34. Diputación de Cádiz. 1974́.

(4) GASCON HEREDIA. Obra citada. Pág. 416.

(5) Jdem. Págs. 417-421.

(6) Juan R. CIRICI. Iuan de la Vega y la arquitectura gaditana del siglo XIX. Págs. 48-49. Colegio Arquitectos Andalucía Occidental. Cádiz, 1992. 
el propio Daura, se levantará la nueva sede de la Escuela a la que se trasladará desde la calle de las Bulas en octubre del mismo año de 1838.

Convertida ya en Academia nacional de Bellas Artes en 1842, primero de San Baldomero y luego de Santa Cristina, a la reorganización de los estudios unirá una nueva regulación de sus funciones en las que cobrará un papel preponderante las distintas Secciones, Pintura, Escultura y Arquitectura, formadas "por las personas más calificadas en el arte respectivo" (7) y encargadas de elaborar los distintos informes sobre los que dictaminará, sometidos a deliberaciones, el pleno de la institución.

Un papel, este último, que a lo largo de todo el siglo la Sección de Arquitectura, en algunos casos convertida en comisión especial, ejercerá con liberalidad y sin renuncias. En la década de los cuarenta la Sección estará formada por Juan Manuel Caballero como presidente, Pedro Alcántara Espinosa como secretario y Juan de la Vega como vocal. En 1950 De la Vega pasa a presidente, Francisco Flores Arenas a secretario y Manuel García del Alamo a vocal. Con posterioridad, 1855, Flores Arenas y García del Alamo son sustituidos por Fernando Ortiz Vierna e Isaac Nessi, para en los años sesenta aparecer, con alternativas, Javier de Urrutia como presidente y Leopoldo Gómez Lobo, Roque Yanguas y Juan de la: Vega como secretarios y vocales; indistintamente. Otras firmas, Cayetano Santolalla, Pascual Olivares y Adulfo del Castillo, se incorporaran a la de De la Vega en los años setenta y ochenta. En el mayor de los casos se trata de arquitectos o profesionales relacionados con la construcción, caso de Flores Arenas que era ingeniero militar, y excepcionalmente de algún artista plástico, como Urrutia que era pintor.

A instancia propia, por la categoría de los monumentos o edificios; distintas ordenanzas o denuncias de particulares, o de otras instituciones, Ayuntamientos, Academia de San Fernando o el propio gobierno, la Sección inspeccionará, deliberará yi evacuará informes, aprobando o desaprobando proyectos y obras, llegando a la paralización de las mismas, y formulando cuantas correcciones y consideraciones fueren necesarias. Los referentes a estas formulaciones vendrán dados por los criterios estéticos oficiales de la Academia y de los propios mentores, siempre coincidentes, las Ordenanzas Municipales y otras legislaciones, y los condicionantes técnicos de solidez, seguridad y adecuación de las construcciones.

Los criterios estéticos constituirán un factor cambiante y responderán a los gustos y movimientos artísticos de las distintas épocas. Su formulación, en el mayor de los casos, resulta poco precisa si no ambigua. De esta manera frecuentemente nos encontramos, con expresiones como "de poca corrección y gusto artístico" o "falta de armonía y decoro", "deformidad que rechaza a la vista", o, por el contrario, "conforme con las reglas del ornato y decoración", "arreglado en todo a las prevenciones hechas en la Ordenanza de Policía Urbana para el mejor ornato" y "sujeta a las reglas del buen gusto y decoración". Una redundancia en la que, como apuntábamos antes, subyacen las preferencias estéticas de la propia Academia, sucursal a su vez de la fernandina madrileña, y de sus integrantes 'y que hasta la mitad del siglo se corresponden con los postulados del neoclasicismo. Teoría y práctica de la arquitectura encontraban su paradigma en el greco-

(7) Reglamento interior de la Ácademia Provincial de Bellas Bellas Artes de Primera Clase de Cádiz. Pág. 28. Cádiz, 1938. 
rromano y en la interpretación de Vitrubio. Sobre cualquier otra consideración la pureza de los perfiles y la regularidad de las proporciones y volúmenes primaban sobre la invención o la licencia ornamental. En palabras de Caveda, el ingenio se mantiene inalterablemente apegado al greco-rromano "en el acorde y proporción de las partes componentes, en el buen compartimiento y el orden interior de los edificios, en la delicadeza y propiedad de los ornatos y en su buen tacto para acomodarlos al carácter y el objeto de la fábrica" (8). Conceptos, todos ellos, que encontraremos en los informes gaditanos hasta bien entrada la segunda mitad del siglo. Si bien en 1844, con la aparición de la Escuela Especial de Arquitectura, asistimos a la reforma de los planes de estudios y con ello a una concepción renovada, eclecticismos e historicismos, y liberalizadora de la arquitectura, sus efectos tardarán en producirse no encontrando un auténtico eco hasta mediados de los años setenta. Abandonados los gustos y rigores estilísticos del neoclasicismo cobrarán mayor valor los aspectos técnicos y de uso práctico.

Las normativas legales con respecto a la buena construcción tenían en las Ordenanzas Municipales su principal referente. Durante el primer tercio del siglo estas Ordenanzas no quedaran al margen de las directrices emanadas de la Academia de San Fernando madrileña, si bien alternaban factores puramente estéticos con otros de orden técnico y junto al "buen gusto" encontraremos también una preocupación por el saneamiento y el trazado urbano. En el caso gaditano, frente a las Ordenanzas de 1792, donde aún se traslucen mayoritariamente criterios de carácter estéticos amparados en el neoclasicismo imperante, las de 1845 ofrecen un cuerpo legal de orden administrativo y técnico con un contenido más urbanístico que específicamente arquitectónico (9).

Por último, en ningún momento y a lo largo de todo el siglo, la Sección, y la Academia en última instancia, olvidaran en sus informes los factores de solidez y adecuación de la construcción a sus usos y destinos. Especialmente en los edificios y obras públicas y en la medida en que los aspectos técnicos se imponen a los estilísticos, segunda mitad del siglo, las especificaciones sobre la solidez de los edificios, seguridad y saneamiento adquieren una mayor presencia.

Y sentadas las premisas es el momento de corroborarlas con el repaso de los informes considerados de mayor interés tanto por su contenido teórico como por su correspondencia material.

Son muchos, más de treinta, los informes elaborados "...acerca de una casa que se trata de construir en..." determinado sitio de la capital o de la provincia. En el mayor de los casos concurren circunstancias especiales que hacen necesaria la opinión de la Academia ya sea por su situación con respecto a otras o al conjunto, novedad de su conformación y ornato, denuncia o petición de otras instituciones, Gobierno o Ayuntamientos. Estadísticamente la Sección dictamina de forma positiva y en los términos siguientes: "Esta comisión ha examinado atenta y detenidamente el adjunto plano que representa la fachada que debe construirse en... y lo encuentra arreglado a las previsiones que la Ordenanza de Policía Urbana establece... y conforme en todo con las reglas de ornato y decoración; por

(8) Memorias para la Historia de la Real Academia de San Fernando y de las Bellas Artes en España. Tomo II. Pág. 9.

(9) Juan R. CIRICI. Obra citada. Pags. 27-33. 
todo lo cual propone su aprobación...". Pero hay casos en los que los informes son más complejos o claramente desaprobatorios.

En diciembre de 1847, el Ayuntamiento de El Puerto de Santa María envía a la Academia "...el alzado que trata D. Marcos Gutiérrez de construir en el solar no 1 y 2 calle de Palacios..." al asaltarle "...alguna repugnancia en acceder a su edificación por creer que la disposición de este proyecto se oponga a las reglas de ornato público". El dictamen de la Comisión empieza por un juicio de intenciones: "La Comisión desearía que todas las casas que forman cada calle en un pueblo tuvieran una misma altura y que ésta fuera proporcionada al ancho de ellas, aun cuando cada edificio en particular tuviera decoración distinta; pero esta regularidad no es posible obtenerla en un pueblo ya construido, porque depende de la mayor o menor posibilidad pecuniaria de los dueños de las fincas, de los cálculos que estos giran y de los fines que se proponen cuando tratan de una edificación; y el obligarles a variar su color de ornato publico con mayor gasto del que quizás pueden soportar, lo considerarían como atentatorio al derecho de propiedad y a la libertad que gozan de especular de la manera que mejor les convenga; pudiéndoseles si obligar a que lo que edifiquen se sujete a las reglas aconsejadas por el buen gusto, que tenga la solidez necesaria para garantizar la seguridad del público y las proporciones para que no presenten una deformidad repugnante a la vista", para entrar de lleno en el asunto, "El proyecto de fachada que nos ocupa no presenta la de un palacio, tampoco la de una casa particular, según sus contiguas de la calle Palacios; pero por la distribución de sus alturas se manifiesta un cuerpo bajo y entresuelo, lo que indica ser un proyecto de fachada que trata de edificarse solo en dichas dos partes reservándose quizás el propietario su continuación en lo sucesivo, para lo cual queda ya preparado; por otro lado observa la comisión que en esta Capital en que existen unas Ordenanzas de Policía Urbana con el carácter de ley para las construcciones civiles, no se coarta mas que la facultad de elevarse sobre las alturas designadas para ciertas calles y plazas, permitiéndose a todo propietario el edificar a medida de sus intereses siempre que lo que intente se sujete a los acordelados, y no sea una deformidad que se oponga a las leyes del buen gusto y reúna las proporciones que la arquitectura exija; por estas razones esta comisión considera el plano adjunto arreglado eurítmicamente, y con respecto a la simetría hace observar que el zócalo que le sirve de basamento es excesivamente alto respecto a lo que demanda las dimensiones del cuerpo bajo, el cual debe si la calle tiene desnivel principiar en la parte mas elevada de la misma con una vara de altura mas, que el cuerpo entramado se corone con una cornisa de 14 pulgadas (10) de alto y 16 de vuelo, que los pretiles se terminen con una faja horizontal de 8 pulgadas de ancho y sobre ellos guardando los centros de los pilares se coloquen jarrones o vasos antiguos de piedra o yeso de proporcionada altura, con lo cual asegura esta comisión que el proyecto presentado es admisible y que contribuirá a embellecer la calle donde debe construirse..." (11). O en el caso de "una casa para la villa de Olvera" a la que la Sección "encuentra con las dimensiones necesarias para la comodidad y con todas las cualidades requeridas para su estabilidad y firmeza, observando

(10) Pulgada: duodécima parte del pié equivalente a algo más de 23 milímetros.

(11) Oficios y Documentos. Año 1847. 18 de diciembre. Archivo Academia de Bellas Artes de Cádiz. 
únicamente que se han desatendido las reglas y preceptos de salubridad no facilitando la necesaria ventilación en la alcoba o dormitorio que aparece trazado en su planta", proponiendo soluciones correctoras (12).

Mayor contundencia encontramos en el informe sobre "la fachada de la casa no 141 calle Ancha -Cádiz- que está acabándose de construir...". Firmado el informe por Juan de la Vega avisa que "se han colocado en la sobrepuerta del balcón principal, en las jambas del mismo y por debajo de su repisa unos mal llamados adornos sin significación alguna y de un gusto tan estrafalario y ridículo que son el escándalo de cuantas personas de recto juicio los miran: si este parto de una imaginación extraviada continúa expuesto al publico puede hacer creer a los forasteros que en Cádiz no se alcanza más en achaque de artes, y es una equivocación que estamos interesados en deshacer...", proponiendo se denuncie al Municipio para la aplicación de las leyes pertinentes (13).

De entre los dictámenes emitidos sobre asuntos de legislación y ordenanzas, resueltos unánimemente en favor de su aplicación y cumplimiento o jugando la Academia un papel de interpretación o arbitraje, destacan tres de especial significación. Teniendo como referencia el debate que durante gran parte del siglo sostendrán los arquitectos con los maestros de obras y éstos con los albañiles prácticos en materia de construcción, la Academia de San Fernando da curso en mayo de 1848 a una resolución en la que detalla las clases de obrajes que pueden ejecutar por sí solos los prácticos sin necesidad de dirección facultativa. La Comisión de Policía Urbana de Cádiz dudaba de los términos y conveniencia de su inclusión, como articulo adicional, en las recientes Ordenanzas Municipales de 1845 y solicita la mediación de la Academia. Se trataba pues de intercalar "...un articulo que ponga coto a los abusos introducidos por algunos dueños o administradores de fincas, maestros de obras y albañiles prácticos con el objeto de dejar ilusorias las determinaciones del Gobierno y de la Real Academia de San Fernando sobre nuevas edificaciones y reparos de los edificios comunes o particulares...". La Sección de Arquitectura, que aprovecha para manifestar los abusos producidos y "el estado de degradación y de ignominia en que algunos profesores... han colocado la ciencia de la construcción...", critica a los albañiles prácticos, que "en contacto con los dueños y administradores... los adulan y embaucan con su charlatanería en términos que les consideren para todo como unos Vitrubios" y a los maestros y profesores que les sirven "de cabeza de hierro ofreciendo pagarles sus dietas o ya conviniéndolas por una cantidad alzada... y abdica con desdoro de su profesión en un mal albañil las facultades directivas que a él solo competen para la buena edificación", para proponer, finalmente, la inclusión de la resolución fernandina en el Capitulo 3.․ Titulo 4.. de las Ordenanzas Municipales por que con ello "...los dueños de las fincas sabrán en qué casos y en qué obras necesitan dirección facultativa; que habiendo de firmar en razón con el Arquitecto o Maestro que haya elegido para dirigirla... se evita el que sean engañados por los albañiles prácticos, se establecerán las relaciones que deben siempre existir entre el dueño y los maestros... y por ultimo existirá en la Alcaldía un registro oficial que servirá para exigir a quien corresponda la responsabilidad por las infracciones..." (14).

(12) Idem. Año 1849. 10 de octubre.

(13) Idem. Año 1855. 12 de enero.

(14) Idem. Año 1849.9 de julio. 
También, y con motivo de la disparidad de los aprecios efectuados por los peritos sobre un terreno incautado por el Municipio en 1862, el Alcalde de Cádiz remite el expediente a la Academia y solicita su mediación. Ante la reedificación de una casa en la calle Novena con esquina a la de Vestuarios y a la de Comedias -hoy Eduardo Dato-Barrié-Plaza del Palillero-, propiedad de Agustín Blázquez, el Ayuntamiento obliga a la cesión de algo más de treinta varas (15) cuadradas "en beneficio del tránsito público". En una primera valoración se cifra la vara en 100 reales para, en una segunda, hacerla subir a 980 reales. En ambos casos la, Sección considera exagerados los aprecios, por extremos, y pasa a la reflexión. Considera necesario "...tener presente que el terreno... es de los de más mérito de la ciudad; si se atiende a ser de los más centricos y de los de más importancia en varios conceptos; pero hay otros que son de mucho mas valor efectivo; como por ejemplo el de la calle Nueva y los de algunas otras inmediaciones..." así como también tiene "...en cuenta los aprecios hechos en el año 1856 para la venta de las casas en la misma calle Novena, $\mathrm{n}^{0} 1,3$ y 5 , que pertenecían al Estado. Esas casas se hallan cabalmente frente a la de que ahora se trata y su terreno fue valorizado en 300 reales la vara...". Aceptando que desde 1856 ha subido el valor de las fincas y de los terrenos, "pero no tanto que pueda considerarse triplicado...", fija, finalmente, en 450 reales el precio a pagar al Sr. Blázquez por cada vara. Para evitar estas cuestiones, "siempre enojosas", la Sección conmina al Ayuntamiento a "la más pronta conclusión del plano geométrico de la ciudad, marcándose en él las nuevas alineaciones... y seguidos los trámites... y obtenida la aprobación... se formase un aprecio general de los terrenos, divididos en zonas, renovándose por trienios, en el cual recayese la aprobación correspondiente..." (16).

El tercer informe de este bloque corresponde a la petición del Alcalde gaditano sobre la mejor conveniencia de los chaflanes en las esquinas de las calles para facilitar el tránsito. Igualmente se trataba de dos artículos adicionales a las Ordenanzas Municipales. Tras una amplia deliberación, en la que la Sección "...considera aceptables tanto la forma circular, como se ha venido verificando desde julio de 1862, como la plana o chaflán que se ha puesto en práctica por acuerdo... en junio de $1878 . .$. ", estima "...que la última forma o sea la de chaflán es la más conveniente...". En su favor argumenta una superior seguridad para los transeuntes, "en una población de calles estrechas en general como lo es Cádiz", al permitir un: mayor espacio y capacidad de movimiento, ventajas en su construcción, "por ser más económico y fácil de ejecutar los chaflanes que la parte cilindrica", mejores posibilidades de ornato y visibilidad, "tanto por la discordancia del carácter que es propio... como por no prestarse a la decoración como la forma plana"! y porque "es la generalmente empleada en todas las ciudades del Reino en las que... se estan construyendo nuevos barrios como en Madrid, Barcelona, Bilbao y varias otras" (17). La propia Sección redacta los dos articulos que deberán adiccionarse a: las Ordenanzas especificando las dimensiones que deben observarse en la recta del chaflán, 2,50 metros, y en el radio de la curva, 1,67, así como las de los huecos que en ambos casos y en los distintos pisos pudiesen incorporarse.

(15) Vara castellana, tambien burgalesa, corresponde a 836 milimetros aproximadamente.'

(16) Oficios y Documentos. Año 1862. 23 de diciembre de 1861. A.A.B.A.C.

(17) Idem. Año 1880. 16 de octubre. 
Finalmente, y atendiendo a los criterios de solidez, seguridad y adecuación, nos encontramos, quizás, con el capítulo más extenso a la vez que entramos decididamente en el terreno de las edificaciones públicas. Dado su carácter y la envergadura de la mayoría de estas obras parece preceptivo evacuar consultas con instancias superiores que, en muchos casos, escaparán a la propia Academia gaditana para hacer el papel de intermediaria con la madrileña de San Fernando. Así en 1848 y para una cárcel que se quiere construir en Medina Sidonia, "...y examinar si reune o no las condiciones de salubridad y ventilación tan necesaria...", se solicita "...que a los diseños de plantas acompañen otros en que se manifieste la fachada principal y una sección dada por el centro del ojo del patio, y que en unos y en otros se indique con tinta de diferente color las partes existentes que se propone aprovechar y las que se quieren construir de nuevo, el grueso de las maderas para los nuevos techos, el espacio que ha de haber entre ellos y la clase de materiales que en todo se ha de emplear" (18); en 1849 para "un informe que se le pide sobre un proyecto de ampliación del Cementerio de la ciudad de Jerez de la Frontera y su costo" la Sección observa disparidad entre la letra del proyecto y los planos y reclama información sobre "... el muro de cerca..., el emplazamiento de los nichos que se desean formar..., de la manera que esta nueva construcción -patio 3.․- se unirá con la antigua..., su alzado y una sección para dar a conocer su decoración exterior e interior y disposición de los nichos..." a la vez que da una serie de indicaciones técnicas "...para la mayor solidez de ésta..." (19); en 1854 se aprueba un proyecto "...para hacer mas cómoda, segura y salubre la distribución interior de la cárcel de Algeciras, aislándola completamente del Instituto de Segunda Enseñanza" (20); también para Jerez de la Frontera y de 1856 es otro detenido informe en el que se analiza la reordenación del Paseo de la Alameda y las vías públicas adyacentes, sopesando y eligiendo entre dos proyectos, el presentado por el propio Ayuntamiento y otro "suscrito por D. Manuel Ma González, vecino y del comercio de dicha ciudad de Jerez, por sí y a nombre de la casa titular González, Dubosse y Compañía", resolviéndose en favor del último "que es el que, a su manera de ver, mayores condiciones de comodidad y embellecimiento reune" (21); en 1860 se aprueba la reforma, describiéndose el proyecto, de una nueva portada para el Cementerio Católico de Cádiz, especificándose la salvedad de "... un rótulo que dice Reinando Isabel segunda, año de 1859; en una obra que no es monumental...: en una mera reforma: en un cementerio, en fin... es impropio presentar como recuerdo para la posteridad el augusto nombre de S.M. la Reina (q.D.g.)", justifica (22); igualmente, en 1861, se aprueban, sendos proyectos de ornamentación, escultor Rosado y pintor Vivaldi, para el Salón de Sesiones -hoy Regio- de la Diputación gaditana haciéndose notar que "...deberá ponerse en consonancia, en cuanto sea posible, la ornamentación de talla de dichos muros con el estilo y pensamiento que domina por la pintura del cielo raso del local" (23); y así otros y otros informes.

(18) Idem. Año 1848. 17 de octubre.

(19) Idem. Año 1849. 17 de octubre.

(20) Idem. Año 1854.. 12 de enero.

(21) Idem. Año 1858. 10 de julio.

(22) Idem. Año 1860. 20 de agosto.

(23) Idem. Año 1861. 23 de abril. 
Mención aparte, por lo voluminoso de los expedientes, requieren los distintos teatros, hasta tres, que sobre el solar de la plaza de San Fernando de Cádiz, hoy Falla, se van a levantar a lo largo de la segunda mitad del siglo XIX. Del primero, un circo-teatro, la Sección encontrará "...admisible el proyecto en cuanto a su forma y distribución de localidades; pero nada le es posible decir de sú solidez, porque no estando acotadas las dimensiones de las maderas; ni deslindados sus cortes y ligazones, ni expresándose tampoco la clase y calidad de la clavazón... sería aventurado dar un dictamen sobre este punto", relegando las condiciones de seguridad "bajo la sola y exclusiva responsabilidad del arquitecto" (24). Para el segundo, un teatro de primer orden, asimismo de madera, se convoca un concurso público en el que la Academia ejercerá el arbitraje y al que se presenta un solo proyecto (25). En enero de 1864 la Sección de Arquitectura emite una descripción pormenorizada del mismo añadiendo algunas observaciones en atención a mejorar su comodidad y holgura, visibilidad, tránsito y exceso de presupuesto (26). Los trámites se dilatan y se suceden nuevos proyectos y nuevos dictámenes, septiembre de 1867 (27). Iniciada su construcción en 1870 e inaugurado en junio de 1871 la Academia, en las personas de Juan de la Vega y Cayetano Santolalla, girará distintas inspecciones sobre las que posteriormente basará sus pormenorizados informes (28). Como dato curioso destaca las quejas del propietario del teatro; Jose $\mathrm{M}^{\mathrm{a}}$ Quintero, por los excesivos honorarios de los arquitectos inspectores. Todo por un montante global de tres mil pesetas.

Por último, y tercero, el actual Teatro Falla, también estará precedido de un concurso público, :1882, si bien en este caso será la Academia de San Fernando de Madrid la encargada de dar el fallo (29). La adjudicación de las obras por parte de la Compañia promotora al proyecto calificado en segundo lugar y premiado con un accéșit originará una nueva polémica en la que la gaditana quedará al margen (30).

Tampoco la arquitectura religiosa escapará al recto juicio de la Academia. En 1855 se denuncia por incumplimiento que "En la Iglesia de N.S. de la Palma de esta ciudad -Cádiz- acaba de construirse un retablo mayor sin que sus planos hayan sido hechos por persona competente ni menos aprobados por esta Academia..." (31) y, un año después, se solicita la suspensión del nuevo retablo mayor, y modificación del presbiterio, que se está construyendo en la Iglesia de San Antonio de Cádiz debido a que no "..se hayan consultado los planos a esta Academia Provincial..." (32). Años después, 1866, el arquitecto Ortiz Vierna si recibirá el visto bueno para "...construir en el patio de la Parroquia de San Antonio de esta ciudad una Capilla para el Sagrario de dicha Iglesia y otra para Ntro: Padre Jesús Nazareno" (33).

(24) Idem. Año 1961. 3 de agosto.

(25) Idem. Año 1963. 29 de octubre.

(26) Idem. Año 1864.7 de enero.

(27) Idem. Año 1867. 17 de septiembre.

(28) Idem. Año 1871. 27 de junio y 22 de septiembre.

(29) Expediente Gran Teatro de Cádiz. Informes sobre obras. Año 1833. Documentos 81-15/4. Archivo Academia de Bellas Artes de San Fernando. Madrid.

(30) J.R. Cirici. Obra citada. Págs. 168-174.

(31) Idem. Año 1855. 26 de agosto.

(32) Idem. Año 1856. 24 de agosto.

(33) Idem. Año 1866. 7 de julio. 
La Capilla Sacramental se revela como una genial síntesis eclecticista en la que el cuerpo del Sagrario de estilo goticista entra en armónica disonancia con el resto de la arquitectura de la sala cuya evocación renancentista nos traslada a los templos florentinos del cuatrocento. Quedaba claro que los tiempos y los gustos estéticos habían cambiado.

Sin embargo donde más desvelos, y tinta, consumirá la Academia será en la culminación de los trabajos de la Catedral Nueva. Su acondicionamiento litúrgico y mobiliario dará pie a toda unas serie de partes e informes cruzados entre artífices, Cabildo Catedralicio y Academia y en los que no permanecerán ajenas ninguna de las distintas Secciones. En 1855 se denuncia, y deshecha, una verja para el coro "... con arreglo a un diseño anónimo que deja mucho que desear respecto al buen gusto artístico" y "ya que afortunadamente con las pingues limosnas con que la piedad de los fieles contribuye vemos con satisfacción y contento completen los accesorios y mobiliario de dicha Iglesia, bueno es tambien que se emplee de una manera conveniente y digna a la importancia y grandiosidad del templo..." (34). Tres años después se procede a la restauración y colocación de un nuevo coro para la Catedral: "La Sección de Arquitectura ha examinado los planos formados por el arquitecto D. Juan de la Vega para la resatauración y colocación en la Santa Iglesia Catedral de esta ciudad del coro procedente de la Cartuja de Sevilla, que remite a examen de esta Academia la Comisión nombrada por el Iltmo. Sr. Obispo de esta Diócesis para entender en esta obra; y hallándolos arreglados y llenos los requisitos que previene la legislación vigente propone la aprobación" (35). Pese a ello se producirá un debate público en la prensa, y en el seno de la propia institución, acerca de la idoneidad de su ubicación y condiciones dentro del templo. El mismo De la Vega se encargará en 1860 de diseñar y dirigir los trabajos de una nueva reja para cerrar el coro. Para elegir "... el genero de pinturas con que debe cubrirse el herraje para que no pierdan su belleza los innumerables ornatos que contiene..." la Sección de Arquitectura "... propone la adopción de la pintura que imita bronce viejo con filete dorado en las aristas y golpes de lo mismo en las partes mas salientes del ornato..." (36). En 1861 son examinados por la Sección "... el plano de la caja del nuevo organo... formado por el arquitecto D. Juan de la Vega y remitido por el Sr. Canonigo D. José Joaquín de Palma" (37) y "... el plano para la construcción de los dos púlpitos que se han de colocar en la Santa Iglesia Catedral..." (38), y en ambos casos, "... tiene el honor de proponer a la Academia su aprobación". Mayores trámites, sin embargo, requerirá la erección del tabernáculo o altar mayor al intervenir la Sección de Escultura en el examen de las figuras y ornato. Iniciados los trabajos en 1862, en 1865 la Sección de Escultura rechaza los modelos de los Doctores de la Iglesia: "Su pequeñez y la carencia absoluta de dibujo en formas, proporciones, paños y accesorios las ponen a mucha distancia de las cualidades que

(34) Idem. Año 1855. 26 de agosto.

(35) Idem. Año 1858. 25 de agosto.

(36) Idem. Año 1860. 4 de enero.

(37) Idem. Año 1861. 7 de febrero.

(38) Idem. 4 de junio. 
deben tener los modelos en este género" (39). Es el mismo caso que acontece a la de Arquitectura con los capiteles en el "...que el modelo presentado dista mucho de llenar las condiciones a que debe satisfacer..., la composición es una mala copia de la de un capitel del orden corintio y sin que haya variado el más insignificante detalle se ve que todos ellos han sido colocados penosamente y con desaliño. La ejecución es amanerada..." (40). Sin embargo un año después, y culminado el proceso de ejecución, la Sección de Arquitectura observa "con gusto la perfección y exactitud con que D. Bartolomé Mercante, encargado de la colocación y ajuste de sus diferentes piezas, ha llevado a cabo ese delicado trabajo, acreditando en ello su pericia e inteligencia..." (41). Curiosamente la mayoría de estos informes vienen firmados por el propio Juan de la Vega quien a la vez de director de las obras catedralicias es el secretario de la Sección.

Resta aún una última aportación o servicio de la Academia que en modo alguno podríamos silenciar. En consonancia con la vigilancia y conservación del patrimonio histórico-artistico de la provincia, la Academia gaditana tomará para sí, y en diferentes ocasiones, la defensa del exclaustrado Monasterio de la Cartuja de Jerez de la Frontera. Conocidas las vicisitudes por las que pasó a lo largo de todo el siglo XIX la Cartuja jerezana desde que por primera vez, en enero de 1810 , los frailes cartujos se vieron obligados a abandonarla y que junto a la pérdida de gran parte de sus tesoros culminan con la demolición de su fábrica para ser vendida como material de acarreo, la Academia, por sí o por otras instancias, elevará su voz denunciando los acontecimientos a la vez que propondrá soluciones para su recuperación y puesta en uso. Si de 1855 es un escrito de la Sección de Arquitectura solicitando "...a la Academia que como protectora de las nobles artes y encargada del museo de esta provincia, reclame a quien corresponda todos los objetos artísticos de estima que todavía restan en dicho Monasterio..." (42), de un año después, y a consecuencia de un encendido artículo aparecido en la prensa local, "Una hazaña de los vándalos ilustrados del siglo XIX" (43), en el que se pone de manifiesto la lamentable situación del establecimiento, es un elaborado e interesantisimo documento en el que una comisión de arquitectos, nombrada en el seno de la Academia y que coinciden con los miembros de la Sección, tras girar una inspección al lugar, incluye una detallada descripción del edificio y sus tesoros, partes y situación, estado de la demolición y solicitud de paralización de la misma proponiendo las reparaciones necesarias para la recuperación del Convento al que consideran "el monumento de más mérito artístico que existe en la provincia" (44). A este informe le seguirán otros siempre en la misma linea de conservación y recuperación del Monasterio.

(39) Idem. Año 1865. 21 de abril.

(40) Idem. 9 de junio.

(41) Idem. Año 1866. 28 de agosto.

(42) Idem. Año 1855. 26 de agosto.

(43) Diario "El Comercio" Año XV. Núm. 4.668. Cádiz, 24 de abril de 1856.

(44) Oficios y Documentos. Año 1856. 17 de mayo. Impreso por acuerdo de la Academia. Imprenta de la Revista Médica. Cádiz, 1856. A.A.B.A.C. 
Sirva esta selección de documentos, y sus comentarios, de justificación argumental de nuestra premisa y su consideración de reconocimiento a la función histórica de las Academias.

N.B. La idea del presente artículo constituyó el cuerpo de la Lección inaugural de la Academia de Bellas Artes Santa Cecilia de El Puerto de Santa Maria, Cádiz, curso 1993-94. 